
\title{
28 Research Suare \\ Fair National Greenhouse Gas Reduction Targets Under Multiple Equity Perspectives - A Synthesis Framework
}

Gaurav Ganti ( $\nabla$ gaurav.ganti@climateanalytics.org )

Climate Analytics https://orcid.org/0000-0001-6638-4076

Andreas Geiges

Climate Analytics

Louise Jeffery

NewClimate Institute

Hanna Fekete

NewClimate Institute

Matthew J. Gidden

Climate Analytics

Michiel Schaeffer

Climate Analytics

Bill Hare

Climate Analytics

Niklas Höhne

NewClimate Institute

\section{Research Article}

Keywords: Equitable Mitigation Targets, Paris Agreement, Nationally Determined Contributions, LongTerm Temperature Goal

Posted Date: May 14th, 2021

DOl: https://doi.org/10.21203/rs.3.rs-397507/v1

License: (c) (i) This work is licensed under a Creative Commons Attribution 4.0 International License. Read Full License 


\section{Abstract}

Equity is one of the key principles underpinning the global climate regime and is all the more essential given the heterogenous, self-differentiated nature of the Paris Agreement. The scientific community has proposed several effort-sharing schemes to operationalise equity - reflecting not only the multi-faceted nature of the problem but also a long history of disagreement that continues to date. We outline a synthesis framework that draws on existing estimates in the literature to develop a "fair share range" for each country within which we identify a common position, which, when applied to the ranges of all countries, results in the collective achievement of the desired temperature goal. A series of methodological choices regarding the treatment of the underlying literature and translation into a temperature equivalence are tested. We demonstrate the consistency of this framework (across different methodological choices) with the principle of "Common but Differentiated Responsibilities" - members of the OECD have the most stringent allocations, while only a few African and Asian countries (including India) have emission allocations that are above their 2010 emission levels. A few OECD members, including the European Union and Great Britain, have emission allocations in 2030 that are either close to, or less than zero. Consistency with their fair share of mitigation will require them to provide appropriate levels of international finance and support to facilitate emission reductions in developing countries. These conclusions are robust to various methodological choices.

\section{Introduction}

The Paris Agreement is heralded as a watershed moment for international climate policy. It represents a delicate balance between ambitious climate targets and a politically acceptable architecture to steer Parties towards the achievement of these targets (Höhne et al., 2017). Ambition in terms of global climate targets was reflected in Article 2.1(a) of the Agreement, which enshrines $1.5^{\circ} \mathrm{C}$ as the Long-Term Temperature Goal (LTTG) while increasing both the margin and likelihood by which warming should be maintained below $2^{\circ} \mathrm{C}$ (Schleussner et al., 2016).

Political acceptability was achieved by shifting from a top-down architecture (exemplified by the Kyoto Protocol) to a bottom-up architecture based on the principle of "self-differentiation", effectively eschewing the "annex-based" classification; Parties chose their contribution (in the form of a Nationally Determined Contribution, or NDC) in line with their national circumstances and capacities guided by a normative expectation on the type of actions that developed and developing countries should take (Rajamani, 2016). Each Party is required to submit an NDC every five years and include information on the fairness and ambition of NDC in light of their national circumstances (UNFCCC, 2014).

This requirement stems from the important role that equity (and its different interpretations) have played in the international climate regime - it is a core component of the 1992 United Nations Framework Convention on Climate Change, where it came to represent a distinct flavour of the principle of "Common but Differentiated Responsibilities" (United Nations Framework Convention, 1992; Winkler, 2020). There is a strong expectation that developed countries take the lead in emissions mitigation. The Paris Agreement, 
while still nodding towards these concepts, deliberately introduces an element of ambiguity on the application of equity and differentiation, to overcome a long history of disagreement over how to define equitable mitigation targets among Parties to the Agreement. This disagreement also exists within the scientific community.

Researchers and policymakers have developed numerous emission allocation schemes, reflecting different starting points and having different ethical underpinnings (for a more detailed overview see (Höhne et al., 2014)). This lack of agreement on a common equitable allocation method was reflected in the first round of (Intended) NDCs, with Winkler et al., (Winkler et al., 2018) finding that fewer than half of the (I)NDCs present an equity-based analysis, only two refer to independent scientific literature and none consider the effect of their approach when applied to other countries.

This is an issue since previous research has highlighted that a purely self-interested approach to selecting equitable allocation schemes by all countries would result in collective failure to meet both the previous $2^{\circ} \mathrm{C}$ temperature limit and the $1.5^{\circ} \mathrm{C}$ temperature limit (Meinshausen et al., 2015). Despite the disagreement over operationalising the concept of equity while setting climate change mitigation targets, there is consensus that equity is important to ratchet up the stringency of country targets (Kartha et al., 2018; Robiou du Pont et al., 2017). This stems from the idea that coordinated action to solve the global commons challenge of climate change can be achieved only if each entity believes that others are taking on their fair share of the effort.

The current literature has adopted various approaches to this issue (see Supplementary Information S/1 for a more extensive overview): Some present a single approach and argue for its relevance, some present quantitative results from different approaches (each implemented individually) and compare them, some papers present various approaches and allow for a heterogenous selection between countries and finally, some provide the full range of the literature from all approaches above. As Kartha et al., (2018) note, the application of equity is irreducibly normative. The normative choices and parameter values selected for an equity framework have a large effect on the resulting outcomes (van den Berg et al., 2019).

In this paper we present a synthesis framework that helps assess whether a country's emission reduction target is consistent with multiple perspectives of equity to meet the LTTG of the Paris Agreement, updating the method that has been developed and applied by the Climate Action Tracker (Climate Action Tracker, n.d.). This framework uses numerical estimates from the literature that spans a wide range and provides an indication of where in that range of potential outcomes the fair share of a country is located such that all other countries make a comparable contribution. The added value of this framework is that, as a synthesis, it pulls together the available literature and derives a range of outcomes for all countries that reflect the literature in a balanced way, while the global total of all individual country emission levels is verified to achieve the LTTG - or a specified warming level above the LTTG. This framework also moves away from the necessity that countries choose a consistent emission allocation scheme (which, as the literature points out, has not happened) and moves to an approach where countries choose a 
similar "level of ambition" within their range consistently, where the specific emission level can be the outcome of different allocation schemes (both across time for a given country and between different countries).

\section{Methodology}

To provide coherent and consistent country-level assessments of equitable achievement of various temperature limits, a systematic approach is used. First, various input data sources are consolidated with additional data supplied through the use of methods available in the literature (sec. 2.1). Next, these data are holistically assessed to develop estimated ranges of equivalent mitigation effort across parties (sec. 2.2). Finally, these equitable effort levels are compiled into global emissions pathways to assess their effect on global temperature (sec 2.3). We discuss in detail below each step of this process, depicted in Fig. 1.

\subsection{Input Data}

\subsubsection{Estimates from the Literature}

This study uses an updated version of the dataset of effort-sharing studies published by 2013 , collected by (Höhne et al., 2014), which was used in the Intergovernmental Panel on Climate Change's (IPCC) 5th Assessment Report. This dataset was complemented to include new literature published by 2020 . The dataset collates different equity allocations that have been published in the peer-reviewed literature and categorises them along two key dimensions: the end of century temperature target $\left(1.5^{\circ} \mathrm{C}\right.$ and $\left.2^{\circ} \mathrm{C}\right)$ and a categorisation scheme of the type of equity allocation.

The categorisation scheme enables the comparison of different allocation schemes based on the dimension of equity that they most closely reflect. Four of the categories are based on the following discrete dimensions: Responsibility, Capability, Equality, and Cost-Effectiveness. Also, three categories that combine elements of these four dimensions are constructed. These are "Equal cumulative per capita emissions" (Equality and Responsibility combined), "Responsibility, Capability and Need" (Responsibility and Capability combined), and Capability - Cost (Capability and cost-effectiveness combined). Costeffectiveness is only used in the combined category, not as a stand-alone category. Finally, a category "Staged" is included that represents the studies that use a blend of the approaches presented above.

The dataset is curated to include studies, or a subset of estimates from a given study if they fulfill the following criteria:

- The study presents more than baseline estimates;

- The emissions in the global target pathway are still low enough to meet the temperature target (We include levels that are consistent with $2^{\circ} \mathrm{C}$ and those with $1.5^{\circ} \mathrm{C}$ separately);

- It is the most recent update of a study by the same authors; 
- The study covers more than only energy-sector $\mathrm{CO}_{2}$ emissions.

In Supplementary Information SI-2 we provide an overview of the studies that are included or excluded and a justification. The curated data that we use as an input to this study contains estimates from 29 studies that were published between 2008 and 2019. Not all categories are represented equally in the studies with many more studies examining the equality, responsibility-capability-need, and staged categories (Fig. 2b) but not all covering all countries (Fig. 2a). This uneven distribution reflects a combination of interest in these approaches, ease of calculation, and the fact that the staged category incorporates quite a wide range of approaches. Apart from the capability-cost and responsibility categories, most countries are represented by at least one data point in each category (Fig. 1a). Capability-costs are often determined using global least-cost models that do not resolve most individual countries.

The number of countries included varies substantially between studies with a significant bias in coverage towards the larger emitting countries. The median number of studies per country is 7 and the mean is 7.8. Countries with the highest coverage include India ( 25 studies), the USA (24 studies), China, and Japan (22 studies) that all have more than 80 different data points for 2030. On the other end, many smaller and younger countries, including Montenegro and Angola for example, are included only in a handful of studies ( 2 and 3 respectively) and have fewer than 10 data points for a given year, reducing the utility of the dataset while making statements about these countries (Fig. 2c).

\subsubsection{Supplementing Literature Data with Additional Effort- Sharing Calculations}

Constructing a fair share range (i.e., a range of outcomes that reflects the spread of outcomes in the literature) requires confidence that the underlying estimates for a country are an adequate reflection of the core principles of equity. As this is not the case for all countries with existing literature, we ensure an adequate numerical representation of the important equity elements in an internally consistent but simplified manner for all countries in the world. We use a simplified allocation scheme to generate allocations for countries, accounting for a wide range of parametric uncertainty and input choices. In addition to these calculations, we also implement three allocation schemes from the literature and use these estimates to complete our input dataset. We present further details of the method and included allocation schemes from the literature in Supplementary Information S/3. The coverage of countries and datapoints is significantly increased by adding these estimates to the literature dataset (Fig. 2d).

\subsubsection{Data harmonisation}

Estimates from the literature and additional complementary analysis are harmonized to the latest available historical data from a composite dataset that draws from assessments by Climate Action Tracker and PRIMAP-hist (Gütschow et al., 2019). We use the term harmonisation to refer to the process of matching greenhouse gas results from the studies with historical data (Gidden et al., 2018). 
First, we need to consider that the scope of gases and sectors covered by the literature vary. Only half of the studies in the literature have the same coverage that is selected for this study. We use only datasets that cover more than energy-related $\mathrm{CO}_{2}$ emissions, so either all gases or all sectors. We also filter the input literature dataset to exclude certain countries (not all countries) from the estimates depending on the relative contribution of the missing emission species for the countries in the last available year. For instance, if a country has a large relative contribution of LULUCF emissions then this country's estimates would be dropped from the studies that include LULUCF.

All estimates in the filtered dataset are harmonised to historical data assuming that the relative contribution of the missing sector or gas is constant over time. We calculate the ratio between the study's assumed base year emissions and the actual historical data in our historical dataset. If the ratio is smaller than 2 or greater than half, we scale the study's estimates by multiplying with the ratio; this is in line with the defaults adopted by other studies (Gidden et al., 2019). If this condition is not fulfilled, we scale the series by adding the offset between the study's estimates and the actual historical data.

\subsection{Identifying a comparable level of effort}

In this section we demonstrate the options we propose to construct a fair share range for a country and identify an "equal level of effort" for each country. The concept of an equal level of effort is defined with respect to the fair share distribution for each country. This distribution is constructed using all available equity studies (see input data above) and therefore used to create a comparable scale of equal effort. An equal level of effort is defined as all country mitigation efforts are located in the same relative location in that distribution. That level can be defined as an equal relative percentile within a range or equal percentile of the distribution as described in the next section. The key issue that results from all countries opting to select the most lenient end of their range is that this would lead to temperature targets being exceeded by a significant margin.

\subsubsection{Constructing a fair share range}

The heterogeneous nature of the underlying equity data set leads to several challenges that pose obstacles to construct a unified measure of fairness. These include the large variation in data availability among countries, the unequal coverage of equity principles. Thus, this study introduces three ways to construct and interpret a fair share range for each country, given the set of estimates from the literature and supplementary calculations, each representing a valid interpretation of the underlying data set.

The three options are presented in Fig. 3 below for the example of India from our dataset. The dimensions that are necessary to define the fair share range are the boundaries of the distribution and the method to "walk" (or move along) the distribution. The distribution is constructed such that each category (not each data point) has equal weight (Fig. 3b)

A key question when determining the boundaries of the fair share range is how studies that lie far away from other studies should influence the fair share range. Under an approach where their effect is included 
explicitly, the highest and lowest emission allocations across categories define the upper and lower end of the fair share range for a country in a given year (grey vertical lines in Fig. 3b). The strength of this approach is that it includes all equity perspectives, while a key limitation of the approach is its sensitivity to extreme or erroneous data. The sensitivity to erroneous data is particularly challenging for studies covering all countries where manual checking of all data points is cumbersome.

An alternate approach is to construct a fair share range, where the fair share range is defined by a percentile (e.g., 5th and 95th) that allows all studies to influence the positions of the fair share range but not to explicitly set the fair share range. This approach implicitly assumes that meaningful insights can be obtained from the distribution of data points from our dataset. To do so, we construct a weighted cumulative distribution function of the equity estimates for each country (black distribution line in Fig. 3b). Each group of equity and temperature categories form a cluster (Fig. 3a) with each estimate weighted in inverse proportion to the population of the cluster - each equity category has an equal weight in determining the shape of the distribution. The choice of the 5th and 95th percentile to define the fair share range is, to some extent, to allow the core of the distribution to have the most influence in determining the fair share range (red line in Fig. 3b).

These two methods to define the boundaries of the fair share range are accompanied by two choices on how to walk the distribution. The lower end of the fair share range can be interpreted to represent an effort level of $100 \%$ (i.e., all countries set targets at the most stringent portion of their fair share range). The upper end of the fair share range can be interpreted to represent an effort level of $0 \%$ (i.e., all countries set a target at the least stringent portion of their fair share range). An equal level of effort assumes that all countries simultaneously select a target emission level corresponding to the same location in their distribution. We present two options to move along this range.

The first option is to assume a linear relationship between the lower and upper end of the fair share range without accounting for the underlying distribution (red and grey lines in Fig. 3b). The argument underlying this approach is that a statistical interpretation essentially overinterprets the available literature. In this approach, different effort level scenarios can be constructed per country that correspond to the percentage on the straight line joining the lower and upper end of the fair share range for the country. The second approach is to use the underlying distribution and to construct effort level scenarios that correspond to the quantile of the underlying distribution that is constructed (black line in Fig. 3b). We construct and discuss results for three cases that combine the two elements outlined above (i.e., options on defining the fair share range and moving along the distribution):

- Min/Max (Distribution Walk): Range constructed from minimum and maximum values and equal level of effort defined by walking the distribution.

- Min/Max (Linear Walk): Range construction as above and equal level of effort defined by linear walk between the levels.

- and 5th/95th percentile (Linear Walk): Range construction based on 5th and 95th percentile of weighted distribution and equal level of effort defined as above. 


\subsection{Identifying effort levels that meet a temperature target}

Defining and walking the range and/or distribution allows us to identify a comparable level of effort for each country. The next step (refer to overview Fig. 1) allows us to determine the long-term temperature implications for meeting a specific point in that distribution. This step is important to (1) define where in the distribution countries should be to meet a certain temperature target, and (2) to evaluate the temperature that would be achieved if all countries were to meet a certain level. The former allows us to define equitable mitigation levels for countries and the latter to compare different countries on the same scale.

From the literature, we identify two broad methods to assess the temperature outcome implied by nearterm emission targets (Höhne \& Gidden et al.). The first involves constructing a full, consistent emissions pathway to the end of the century and evaluating the temperature ("Scenario Construction"). The second identifies emissions levels in a particular year that would be consistent with different end temperatures and uses these to establish cut-offs ("Scenario Inference"). We explain each in detail below but first outline how emissions from Land-Use, Land-Use Change and Forestry (LULUCF), and international bunkers, not otherwise covered by the effort-sharing ranges, are accounted for in the temperature assessment.

\subsubsection{From national emissions allocations to a global trajectory}

International bunkers (aviation and marine) and LULUCF emissions are added to the sum of national emissions (excluding LULUCF) to complete the global emissions pathways. Equity studies deal with national emissions and often do not focus on international bunkers explicitly and therefore do not provide any guidance on an equitable reduction of those.

Emissions from LULUCF used in this study are based on the median of the reference scenario LULUCF pathways from the LIMITS project (Kriegler et al., 2014). In this pathway, LULUCF emissions decrease to $70.4 \%$ below 2010 levels by 2030 and further decrease to $88 \%$ below 2010 levels by 2050 . The maximum net-negative emissions from LULUCF are $433 \mathrm{MtCO}_{2}$ in 2100 . This pathway meets the sustainability criteria for Carbon Dioxide Removal (CDR) through Afforestation and Reforestation (AR) in 2050 as assessed by (Fuss et al., 2018).

The relatively conservative LULUCF emissions that we select for the central cases presented in this paper reflect a normative choice, where we prefer a stronger reliance for emission reductions until 2050 at the country-level as opposed to a heavy reliance on CDR in the second half of the century. For international aviation and shipping emissions, we use data from the "pledge" assessment of the Climate Action Tracker (Climate Action Tracker, 2020a).

\subsubsection{Temperature Assessment}


In this section, we highlight two options to identify an effort level within the country ranges that correspond to the achievement of a temperature target. The premise of both the options is that 2030 (and 2025,2050 ) emission levels is the existence of a robust relationship between 2030 emission levels and warming targets but differences in how the relationship is derived. A detailed discussion on the implications of different methods to link 2030 emission levels to 2100 warming levels is presented in (Jeffery et al., 2018).

\subsubsection{Scenario Construction Method}

Multiple emission scenarios (at different effort-levels with a step of 10 percentile/percentage) are constructed using the emission allocation approaches outlined in the previous section. These pathways are constructed until 2050 and are extended until 2100 using the Constant Quantile Extension method (Gütschow et al., 2018). The premise of this method is that the same level of effort in reducing emissions is maintained till the end of the century.

The resulting global GHG emission pathways are used to create full multi-gas emission pathways using the Equal Quantile Walk method (Meinshausen et al., 2006). The resulting multi-gas emission pathway is provided as an input to a climate model using the climate sensitivity range assessed by the IPCC in the 5th Assessment Report (IPCC, 2013). The reduced complexity carbon cycle and climate model MAGICC6 is used to project the corresponding temperature pathway (across different probabilities) for the global mean temperature (GMT) (M. Meinshausen et al., 2011).

This allows the relationship between the equitable ambition level and the projected GMT warming response to be evaluated. This allows us to use any useful search routing to refine the effort levels that would be required to achieve a specified temperature target. We assess a $1.5^{\circ} \mathrm{C}$ level that is consistent with a $50 \%$ chance of keeping warming below $1.5^{\circ} \mathrm{C}$ in 2100 and at least $33 \%$ chance of keeping warming below $1.5^{\circ} \mathrm{C}$ throughout the century (SR15 category: $1.5^{\circ} \mathrm{C}$ low overshoot) and a $2^{\circ} \mathrm{C}$ level that gives a $66 \%$ chance of keeping warming below $2^{\circ} \mathrm{C}$ throughout the century (SR15 category: Lower $2^{\circ} \mathrm{C}$ ). We also present the effort levels that lead to higher end of century warming $\left(3^{\circ} \mathrm{C}, 4^{\circ} \mathrm{C}\right.$ and $5^{\circ} \mathrm{C}$, with a $66 \%$ likelihood).

\subsubsection{Scenario Inference Method}

A second approach to link effort levels to a warming level focuses on the emissions in a given year (here we focus on 2030) implied by each effort level scenario (and any other year under consideration) and compares it to emission levels derived from scenarios underlying SR1.5 that meet the desired long-term temperature target.

The "Scenario Inference" approach comprises three stages:

1. Identifying an emission level in the target year that is consistent with the selected temperature level. To facilitate comparison with the Scenario Construction method, we evaluate the Scenario Inference approach for the emission levels arrived at by the Scenario Construction approach. For the ${ }^{\prime \prime} 1.5^{\circ} \mathrm{C}$ 
low overshoot" and the "Below $2^{\circ} \mathrm{C}^{\prime}$ categories, the median of the pathway emissions in 2030 amount to 32.7 and $39.3 \mathrm{GtCO}_{2}$ eq respectively.

2. The total global emissions are adjusted to exclude emissions from LULUCF and bunkers. For this assessment, we use the 2030 emission values from the pathways presented in the preceding sections that amount to $1.1 \mathrm{Gt} \mathrm{CO}_{2}$ eq and $1.7 \mathrm{Gt} \mathrm{CO}_{2}$ eq respectively. This results in a target emission level (excluding LULUCF and bunker emissions) of 29.9 and $36.5 \mathrm{Gt} \mathrm{CO}_{2}$ eq in 2030 for the " $1.5^{\circ} \mathrm{Clow}$ overshoot" and "Below $2^{\circ} \mathrm{C}$ " categories respectively.

3. We identify the equal percentile of the country distributions at which the sum of country emissions matches the total emission level calculated in Step 2.

\subsubsection{Assessing Geopolitical Sub-Units}

There are two options to assess geopolitical units (e.g., the European Union) and their sub-units (countries). The first option is to sum up the emissions of the sub-units to arrive at the geopolitical unit's emission allowances under our framework. This approach is followed by Holz et al., (2017). We select this option for the presentation of results.

The second option is to scale the emissions of the geopolitical unit derived using our framework to identify a new common effort level among the sub-units that sum up to the geopolitical unit's level. This approach honours the fact that a geopolitical unit such as the European Union sets a target vis-à-vis the rest of the world, and then shares the effort related to this target amongst its constituent members. A mathematical description of the approach is presented in Supplementary Information SI-4. Such an approach is weakened when a negotiating geopolitical unit is new or newly changed (e.g., the EU28 resulting in the EU27 post Brexit), due to the lack of available equity literature developed for mature negotiating blocks.

\section{Results}

\subsection{Comparison Between Regional Results and Cost- Effective Allocations}

The touchstone against which all equitable allocation frameworks are judged is their consistency with the principle of CBDR, with developed countries taking the lead in mitigation and providing support to developing countries. We calculate the change (with respect to 2010 emission levels) for five aggregated country groupings that are commonly used in IPCC assessments and result in the achievement of the $1.5^{\circ} \mathrm{C}$ target of the Paris Agreement.

The first key insight is that the median of the fair share emission reductions (measured as a \% below 2010 levels) are most stringent for the OECD region across all three cases implying that the OECD countries take the lead in reducing emissions and countries belonging to the Middle East and Africa region tend to have the most lenient allocations across all three cases, with some countries given allocations that are 6 times as large as their historical emissions in 2010 - examples of these countries 
include Uganda, Tanzania, Somalia, and Ethiopia, among others. This tendency is observed for two reasons:

- First, such allocations are a reflection of the relatively low contribution of these countries to climate change, and, specifically their low capability to mitigate (reflecting a need for strong international support mechanisms);

- Second, for these countries, the upper end of the range is determined by the study by (Robiou du Pont et al., 2016). The implementation of the "Capability" approach that is based on the approach outlined by (Jacoby et al., 2008) and leads to quite high allocations for smaller developing countries, and the distribution of equity estimates that is skewed towards higher values.

The spread of fair share emission reductions within each region varies strongly across the cases. The 10-90\% range for each region is significantly reduced in the Min/Max (Distribution Walk) case when compared to the other cases. The 10-90\% ranges for the Min/Max (Linear Walk) and 5th /95th percentile (Linear Walk) cases for the OECD are $[-178 \%,-17 \%]$ and $[-121 \%,-21 \%]$ respectively while the corresponding values for the Min/Max (Distribution Walk) case are [-64\%,-26\%]. The opposite effect is observed for the other region, with the effect most pronounced for the Middle East and Africa region. Here, the 10-90\% range shrinks from $[-31 \%, 1093 \%]$ and [-36\%, 799\%] for the Min/Max (Linear Walk) and 5th $/ 95$ th percentile (Linear Walk) cases to $[-36 \%, 100 \%]$ in the Min/Max (Distribution Walk) case. The key reason for this is the skewed nature of the equity distribution for the OECD countries, with a few equity principles (by design) providing highly negative allocations - when we choose to walk the distribution this essentially "walks" over the small number of negative allocations, and, to some extent when compared to the other two methods redistributes effort from the OECD countries to other regions. The opposite effect is observed for developing countries including India and African countries (highlighted above).

We further compare the fair share emission allocations to the median of the emission levels for these regions, as assessed by the IPCC's Special Report on $1.5^{\circ} \mathrm{C}$ (purple line in Fig. 4) (IPCC, 2018). These emission pathways are generated using Integrated Assessment Models that essentially provide a perspective on the cost-effective distribution of mitigation effort with the lowest aggregated global mitigation cost assuming optimal operation of global markets (Clarke et al., 2014). The key insight that emerges from this comparison is that the required fair reduction for the OECD countries (median: $-83 \%$ to $-54 \%$ across the three cases) is more stringent than the median of the cost-effective allocation for the region according to the 'cost effective' perspective (median: - 49\%). The opposite is true for the other regions, with the largest gap observed for members of the Middle-East and Africa Region. This indicates that OECD countries will need to ensure emission reduction in other regions to fulfill their fair share of emission reductions.

\subsection{Country-level results}

In the following section. we present the country-level fair share levels for different temperature levels and discuss the variation across the three cases for a selection of countries. We further compare these to the 2030 emission levels implied by the NDCs submitted by these countries. We select the European Union 
(EU27) and the United Kingdom from the OECD countries and the BRICS member states (Brazil, Russia, India, China, and South Africa) in Fig. 5. We also include results for the United States of America (USA), although they are yet to submit an NDC following their re-entry as a Party to the Paris Agreement - we use the Current Policy Projections (CPP) emission levels from the Climate Action Tracker (Climate Action Tracker, 2020b), to assess a hypothetical NDC that were set at these levels. Further results per country are included in the Supplementary Information File that accompanies this article.

The Russian Federation's NDC target translates into an 18-25\% increase in emissions by 2030 , compared to 2010 levels. Irrespective of the case, if all other countries were to put forward a target with the same level of effort this would result in warming greater than $4^{\circ} \mathrm{C}$ (with a $66 \%$ chance). If the USA were to set a target that is consistent with their CPP then this target would be assessed as being consistent with $4^{\circ} \mathrm{C}$ warming (with a $66 \%$ chance) and greater than $4^{\circ} \mathrm{C}$ for the upper end in some cases.

On the other hand, the choice on how to interpret and walk the distribution has a strong effect on the fair share levels for India. India's NDC target translates into a 146-161\% increase in emissions by 2030 compared to 2010 levels. In the 5th /95th percentile (Linear Walk) and Min/Max (Distribution Walk) cases respectively, if all countries were to put forward a target with the same level of effort this would result in warming below $4^{\circ} \mathrm{C}$ (with a $66 \%$ chance). However, in the Min/Max (Linear Walk) case the lower level of the NDC would be consistent with keeping warming below $2^{\circ} \mathrm{C}$ with a $66 \%$ chance. The reason for this variation is because a study that is a relative outlier sets the range in the Min/Max (Linear Walk) case (see Fig. 3) resulting in more generous allocations.

Another type of uncertainty is related to the large span of quantified emissions reductions implied by the NDC can be observed in the case of South Africa. South Africa's NDC follows a 'peak-plateau-decline' trajectory that would result in emissions plateauing between $26 \%$ below to $12 \%$ above 2010 levels by 2030. Here, the wide band of uncertainty means that the upper and lower levels can span different temperature assessments (for example, the upper level can be assessed to be consistent with $4^{\circ} \mathrm{C}$ of warming in the Min/Max (Linear Walk) case, while the lower level can be assessed to be consistent with $2^{\circ} \mathrm{C}$ of warming in the same case).

Developed countries/groups including the EU27 and the United Kingdom have $1.5^{\circ} \mathrm{C}$ fair emission allocations that are either close to, or net negative, by 2030 (in the Min/Max (Linear Walk) and 5th /95th percentile (Linear Walk). This indicates that these countries need to provide financial support to developing countries in addition to strong domestic mitigation to ensure that they stay within their fair share of emission allowances.

\subsection{Effect of temperature assessment method}

The temperature assessment method primarily impacts the relationship between global total emissions in a given year and the associated warming. Under the scenario inference approach, total emissions in the year investigated will, by design, always be the same as those specified in the input. Under the scenario construction approach, emissions levels are adjusted in all years to match the effort-sharing 
ranges and are then extended from 2050 to the latter part of the century, following a principle of continued effort through time. The constructed equity pathway does not necessarily match the shape or distribution of global least-cost modelled pathways as it is constrained by the equity ranges.

If the scenario inference approach is forced to match the total emissions of the pathway extension approach, the results for individual countries are the same as there is no difference in the method to share the total between countries. However, if a particular warming threshold is targeted (for example, IPCC $1.5^{\circ} \mathrm{C}$ low overshoot pathways), the choice of temperature assessment method can lead to substantially different results for individual countries. The appropriate method to use depends on the purpose of the analysis; a study focussed on one year only can benefit from the clarity and simplicity of the scenario inference method, but the scenario construction method produces consistent results through time. However, if the scenario construction method leads to higher emissions in the near-term (e.g. 2030) then if all countries were to meet their $1.5^{\circ} \mathrm{C}$ level then there is an implicit expectation that emissions reductions and /or carbon dioxide removal levels in the latter half of the century will be higher.

\section{Discussion And Conclusion}

In this paper we have presented a synthesis framework to assess equitable emission allocations to countries in the absence of a single allocation scheme that is acceptable to all countries. This does not invalidate any country or stakeholder's specific perspective on equity, but rather provides an overview of where all countries stand in comparison to each other. A key feature of this framework is that it provides emissions allocation estimates in line with the achievement of the Long-Term Temperature Goal of the Paris Agreement while covering a broad range of perspectives of equal efforts and also ensuring consistency with the principle of "Common but Differentiated Responsibility", with the developed countries having the most stringent allocations. Equity is already an integral part of countries' formulation of NDCs and will continue to have relevance in the context of target setting in the Paris Agreement, with recent suggestions that it be a pillar as well of longer-term targets (Rogelj et al., 2021). While this framework covers only the perspectives that have been quantified in the literature it still can provide an indicative input both to the global stocktake in 2023, and beyond as countries revise their NDCs.

We have demonstrated the implications of alternate choices that influence the results of our framework. A key element that causes variation in the fair share levels needed to meet $1.5^{\circ} \mathrm{C}$ is the interpretation of the distribution of the equity literature - the choice to walk the fair share distribution has the implicit effect of redistributing effort (relative to the other cases) from developed to developing countries and demonstrates a potential drawback of a strict distributional interpretation of the equity estimates. This largely affects countries with a distribution that has a long tail towards negative emissions.

However, there is a danger to ignoring the distribution entirely - an approach where we select only the minimum and maximum literature data points to define the range and then traverse the range linearly is prone to the significant influence of a long tail at either end of the equity distribution. An argument for 
this approach is that each data point is equally valid, and these endpoints should not be ignored, but a consequence is that the contribution of the rest of the literature is effectively ignored. The effect of a long tail towards highly negative estimates (e.g., EU27) is to provide significantly more stringent emission allowances, while the effect of a long tail towards highly positive estimates (e.g., India, Ethiopia) is to provide significantly less stringent emission allowances. Our third option (5th /95th percentile, Linear Walk) incorporates an element of the distributional definition of the fair share range by truncating long tails and then assumes a linear trajectory between the levels to allow all data points to impact the results.

Finally, we present two methods for establishing a warming level that corresponds to an 'equal level of effort' through the effort-sharing ranges for each country - scenario construction and scenario inference. For a specific emissions level in a given year, the two approaches produce the same results. However, when used to identify emissions shares across time, the two differ. The scenario construction approach uses the principle of the same level of effort in equity space through time and, for the same warming limit, will also produce a different global emissions pathway than those derived through integrated assessment models. The scenario inference approach is simpler and can be used to distribute a specific emissions total in a specific year but does not maintain the principle of equal effort through time.

We have outlined a series of methodological options for utilising broad equity literature to define comparable emissions reductions across all countries. For each option, we've outlined the various advantages and weaknesses and highlighted the limitations in certain cases, such as limited data availability. Some components, however, remain robust across all methodological choices. The median of the OECD country reductions is at least $54 \%$ below 2010 levels (for one case, and $71 \%$ and $83 \%$ for the other cases), with some countries (depending on the methodological choices) already reaching close to zero emissions by 2030 , and net negative emissions thereafter. On the other hand, only countries in the Middle East and Africa Region, and, to a lesser extent, the Asia region can increase their emissions relative to 2010. It is important to note that the interpretation of these results does not imply mitigation beyond technical feasibility in OECD countries - it does, however, imply that OECD countries need to provide adequate finance and support to the countries that are allowed to grow their emissions, in correspondence to any portion of their fair-share mitigation reductions that they do not achieve domestically.

\section{References}

Clarke, L., Jiang, K., Akimoto, K., Babiker, M., Blanford, G., Fisher-Vanden, K., Löschel, A., McCollum, D., Paltsev, S., Rose, S., Shukla, P. R., Tavoni, M., van der Zwaan, B., \& van Vuuren, D. P. (2014). Assessing Transformation Pathways. In O. Edenhofer, R. Pichs-Madruga, Y. Sokona, E.Farahani, S. Kadner, K. Seyboth, A. Adler, I. Baum, S. Brunner, P. Eickemeier, B. Kriemann, J. Savolainen, S. Schlömer, C. von Stechow, T. Zwickel, \& J. C. Minx (Eds.), Climate Change 2014: Mitigation of Climate Change. Contribution of Working Group III to the Fifth Asessment Report of the IPCC. Cambridge University Press. 
Climate Action Tracker. (n.d.). Comparability of effort / Climate Action Tracker. Retrieved March 29, 2021, from https://climateactiontracker.org/methodology/comparability-of-effort/

Climate Action Tracker. (2020a). International Shipping / Climate Action Tracker. https://climateactiontracker.org/sectors/shipping/

Climate Action Tracker. (2020b). USA / Climate Action Tracker. https://climateactiontracker.org/countries/usa/

Fuss, S., Lamb, W. F., Callaghan, M. W., Hilaire, J., Creutzig, F., Amann, T., Beringer, T., De Oliveira Garcia, W., Hartmann, J., Khanna, T., Luderer, G., Nemet, G. F., Rogelj, J., Smith, P., Vicente, J. V., Wilcox, J., Del Mar Zamora Dominguez, M., \& Minx, J. C. (2018). Negative emissions - Part 2: Costs, potentials and side effects. Environmental Research Letters, 13(6). https://doi.org/10.1088/1748-9326/aabf9f

Gidden, M., Fujimori, S., van den Berg, M., Klein, D., Smith, S. J., van Vuuren, D. P., \& Riahi, K. (2018). A methodology and implementation of automated emissions harmonization for use in Integrated Assessment Models. Environmental Modelling and Software, 105, 187-200.

https://doi.org/10.1016/j.envsoft.2018.04.002

Gidden, M., Riahi, K., Smith, S. J., Fujimori, S., Luderer, G., Kriegler, E., van Vuuren, D. P., van den Berg, M., Feng, L., Klein, D., Calvin, K., Doelman, J. C., Frank, S., Fricko, O., Harmsen, M., Hasegawa, T., Havlik, P., Hilaire, J., Hoesly, R., ... Takahashi, K. (2019). Global emissions pathways under different socioeconomic scenarios for use in CMIP6: a dataset of harmonized emissions trajectories through the end of the century. Geoscientific Model Development, 12, 1443-1475.

https://gmd.copernicus.org/articles/12/1443/2019/

Gütschow, J., Jeffery, L., \& Gieseke, R. (2019). The PRIMAP-hist national historical emissions time series (1850-2016) V 2.0. GFZ Data Services.

Gütschow, J., Jeffery, M. L., Schaeffer, M., \& Hare, B. (2018). Extending Near-Term Emissions Scenarios to Assess Warming Implications of Paris Agreement NDCs. Earth's Future, 6(9), 1242-1259.

https://doi.org/10.1002/2017EF000781

Höhne, N., den Elzen, M., \& Escalante, D. (2014). Regional GHG reduction targets based on effort sharing: a comparison of studies. Climate Policy, 14(1), 122-147.

https://doi.org/10.1080/14693062.2014.849452

Höhne, N., Gidden, M., \& Elzen, M. (2021). Wave of net zero greenhouse gas emission targets opens window on meeting the Paris Agreement. Submitted for Publication. https://doi.org/10.21203/rs.3.rs$128328 / v 1$

Höhne, N., Kuramochi, T., Warnecke, C., Röser, F., Fekete, H., Hagemann, M., Day, T., Tewari, R., Kurdziel, M., Sterl, S., \& Gonzales, S. (2017). The Paris Agreement: resolving the inconsistency between global goals 
and national contributions. Climate Policy, 17(1), 16-32.

Holz, C., Kartha, S., \& Athanasiou, T. (2017). Fairly sharing 1.5: national fair shares of a $1.5^{\circ} \mathrm{C}$-compliant global mitigation effort. International Environmental Agreements: Politics, Law and Economics. https://doi.org/10.1007/s10784-017-9371-z

IPCC. (2013). Climate Change 2013. The Physical Science Basis.

IPCC. (2018). Global Warming of $1.5^{\circ} \mathrm{C}$. An IPCC Special Report on the impacts of global warming of $1.5^{\circ} \mathrm{C}$ above pre-industrial levels and related global greenhouse gas emission pathways (T. W. MassonDelmotte, V., P. Zhai, H.-O. Pörtner, D. Roberts, J. Skea, P.R. Shukla, A. Pirani, W. Moufouma-Okia, C. Péan, R. Pidcock, S. Connors, J.B.R. Matthews, Y. Chen, X. Zhou, M.I. Gomis, E. Lonnoy, T. Maycock, M. Tignor (ed.)). Intergovernmental Panel on Climate Change. https://www.ipcc.ch/sr15/

Jacoby, H. D., Babiker, M. H., Paltsev, S., \& Reilly, J. M. (2008). Sharing the Burden of GHG Reductions (Issue 167).

Jeffery, M. L., Gütschow, J., Rocha, M. R., \& Gieseke, R. (2018). Measuring Success: Improving Assessments of Aggregate Greenhouse Gas Emissions Reduction Goals. Earth's Future, 6(9), 1260-1274. https://doi.org/10.1029/2018EF000865

Kartha, S., Athanasiou, T., Caney, S., Cripps, E., Dooley, K., Dubash, N. K., Fei, T., Harris, P. G., Holz, C., Lahn, B., Moellendorf, D., Müller, B., Roberts, J. T., Sagar, A., Shue, H., Singer, P., \& Winkler, H. (2018). Cascading biases against poorer countries. Nature Climate Change, 8(5), 348-349. https://doi.org/10.1038/s41558018-0152-7

Kriegler, E., Tavoni, M., Aboumahboub, T., Luderer, G., Calvin, K., DeMaere, G., Krey, V., Riahi, K., Rösler, H., Schaeffer, M., \& van Vuuren, D. P. (2014). What Does the 2 C Target Imply for a Global Climate Agreement in 2020. Climate Change Economics, 4. https://doi.org/10.1142/S2010007813400083

Meinshausen, M., Raper, S. C. B., \& Wigley, T. M. L. (2011). Emulating coupled atmosphere-ocean and carbon cycle models with a simpler model, MAGICC6 - Part 1: Model description and calibration. Atmospheric Chemistry and Physics, 11(4), 1417-1456. https://doi.org/10.5194/acp-11-1417-2011

Meinshausen, Malte, Hare, B., Wigley, T. M. L., Van Vuuren, D., Den Elzen, M. G. J., \& Swart, R. (2006). Multi-gas emissions pathways to meet climate targets. In Climatic Change (Vol. 75, Issues 1-2, pp. 151194). Springer. https://doi.org/10.1007/s10584-005-9013-2

Meinshausen, Malte, Jeffery, L., Guetschow, J., Robiou Du Pont, Y., Rogelj, J., Schaeffer, M., Höhne, N., Den Elzen, M., Oberthür, S., \& Meinshausen, N. (2015). National post-2020 greenhouse gas targets and diversity-aware leadership. Nature Climate Change, 5(12), 1098-1106.

https://doi.org/10.1038/nclimate2826 
Rajamani, L. (2016). AMBITION and DIFFERENTIATION in the 2015 Paris AGREEMENT: INTERPRETATIVE POSSIBILITIES and UNDERLYING POLITICS. International and Comparative Law Quarterly, 65(2), 493514. https://doi.org/10.1017/S0020589316000130

Robiou du Pont, Y., Jeffery, M. L., Gütschow, J., Rogelj, J., Christoff, P., \& Meinshausen, M. (2016). Equitable mitigation to achieve the Paris Agreement goals. Nature Climate Change, 7(1), 38-43. https://doi.org/10.1038/nclimate3186

Robiou du Pont, Y., Jeffery, M. L., Gütschow, J., Rogelj, J., Christoff, P., \& Meinshausen, M. (2017). Equitable mitigation to achieve the Paris Agreement goals. Nature Climate Change, 7(1), 38-43. https://doi.org/10.1038/nclimate3186

Rogelj, J., Geden, O., Cowie, A., \& Reisinger, A. (2021). Net-zero emissions targets are vague: three ways to fix. Nature, 591(7850), 365-368. https://doi.org/10.1038/d41586-021-00662-3

Schleussner, C.-F., Rogelj, J., Schaeffer, M., Lissner, T., Licker, R., Fischer, E. M., Knutti, R., Levermann, A., Frieler, K., \& Hare, W. (2016). Science and policy characteristics of the Paris Agreement temperature goal. Nature Climate Change, 6(9), 827-835. https://doi.org/10.1038/nclimate3096

United Nations Framework Convention, (1992).

UNFCCC. (2014). Lima call for climate action. In Decision -/CP.20.

van den Berg, N. J., van Soest, H. L., Hof, A. F., den Elzen, M. G. J., van Vuuren, D. P., Chen, W., Drouet, L., Emmerling, J., Fujimori, S., Höhne, N., Kõberle, A. C., McCollum, D., Schaeffer, R., Shekhar, S., Vishwanathan, S. S., Vrontisi, Z., \& Blok, K. (2019). Implications of various effort-sharing approaches for national carbon budgets and emission pathways. Climatic Change. https://doi.org/10.1007/s10584-01902368-y

Winkler, H. (2020). Putting equity into practice in the global stocktake under the Paris Agreement. Climate Policy, 20(1), 124-132. https://doi.org/10.1080/14693062.2019.1680337

Winkler, H., Höhne, N., Cunliffe, G., Kuramochi, T., April, A., \& de Villafranca Casas, M. J. (2018). Countries start to explain how their climate contributions are fair: more rigour needed. International Environmental Agreements: Politics, Law and Economics, 18(1), 99-115. https://doi.org/10.1007/s10784-017-9381-x

\section{Figures}



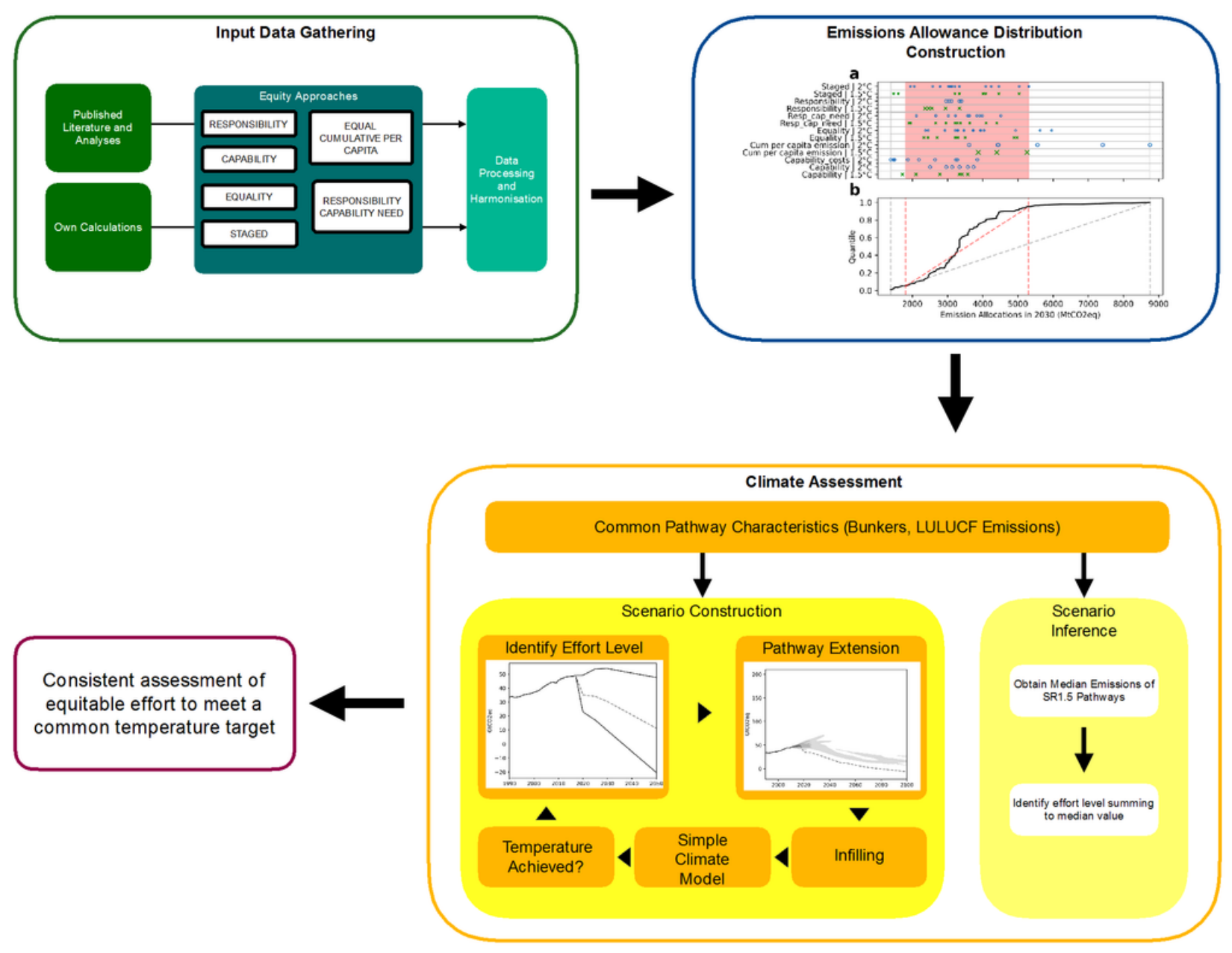

Figure 1

Overview of the analytical framework presented in this paper. 

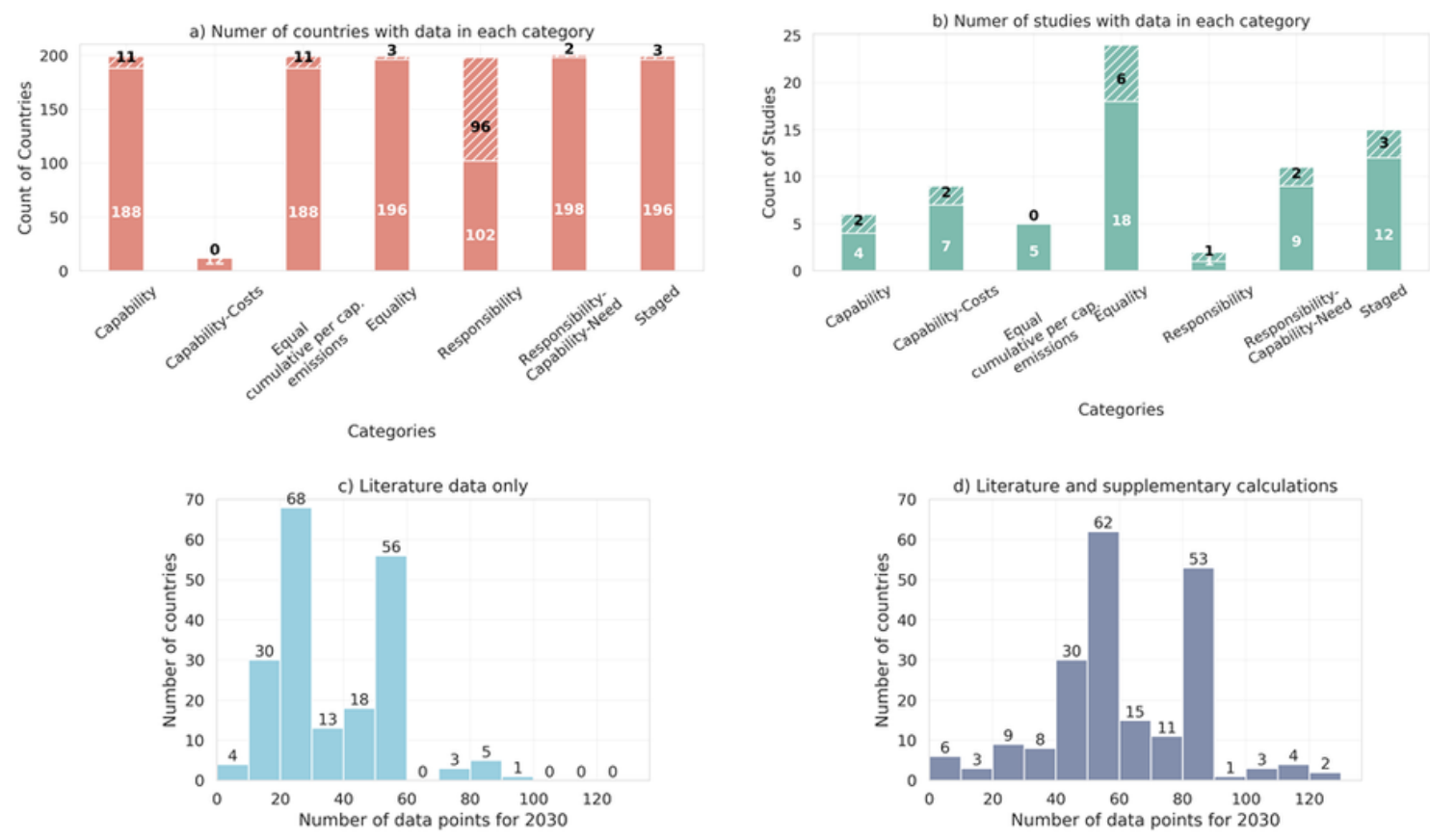

\section{Figure 2}

Coverage of categories and countries in 2030 by existing literature data included in our analysis. (a) the number of countries with at least one data point in each equity category and (b) the number of studies with data in each category. The hashed area shows those excluded by the data curation process. Summary of the number of data points for each country available for the year 2030 (c) in the literature data alone and (d) when supplementary calculations are included (Section 2.1.2). 
a
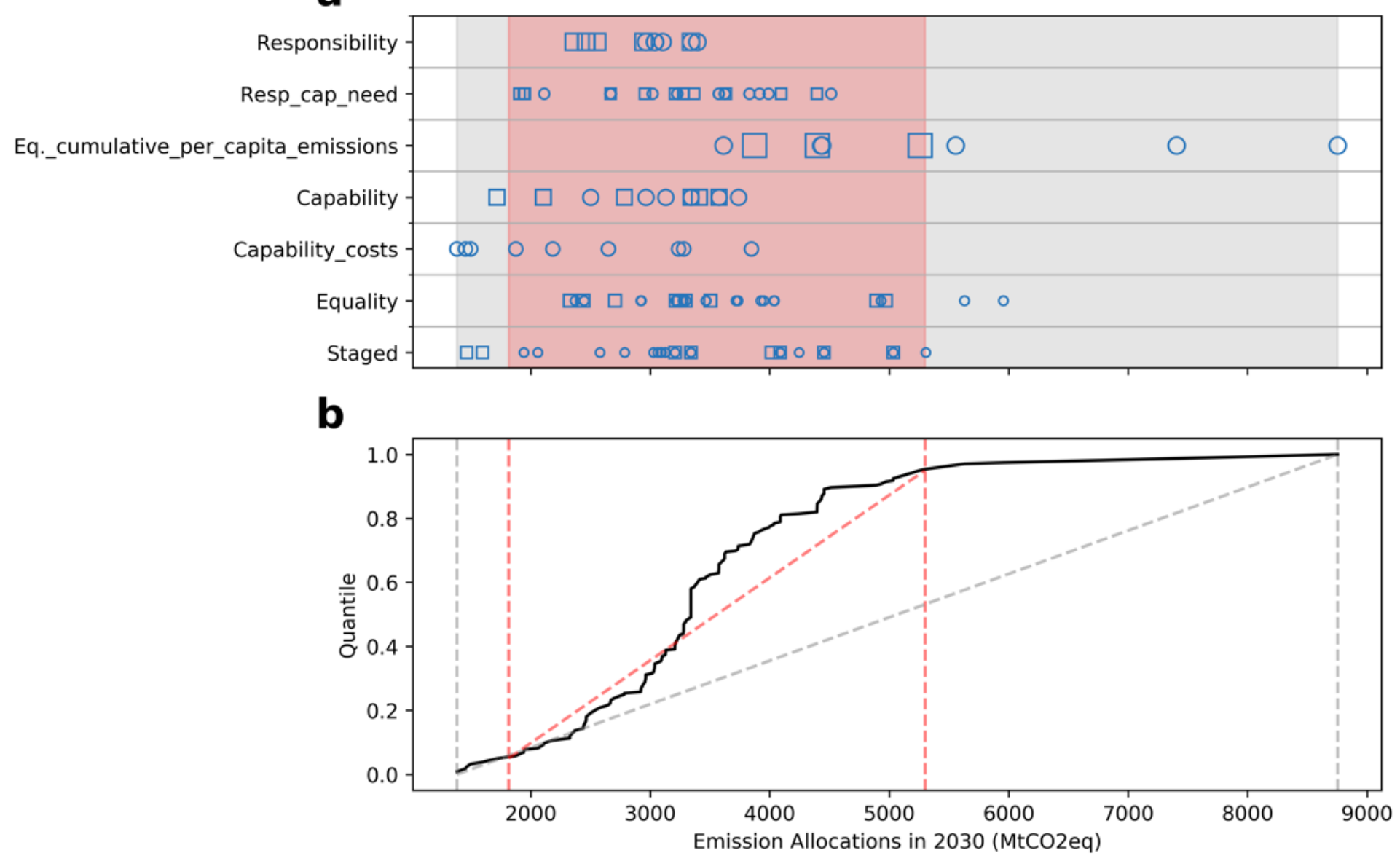

\section{Figure 3}

Demonstration of fair share range construction for India. Literature-based estimates for fair emission allowances are shown according to their equity category. Squares indicate studies related to $1.5 \mathrm{C}$ warming, while circles depict $2 \mathrm{C}$ studies. The symbol size reflects the weighting of studies that enforces that all studies in one category sum up to the same value. The lower panel depicts the Cumulative Distribution Function (CDF) according to the same weighting as the black line. The dotted red and grey lines depict CDF of uniform distributions between $\mathrm{p} 5$ and $\mathrm{p} 95$ and respectively the minimum and maximum. 
a

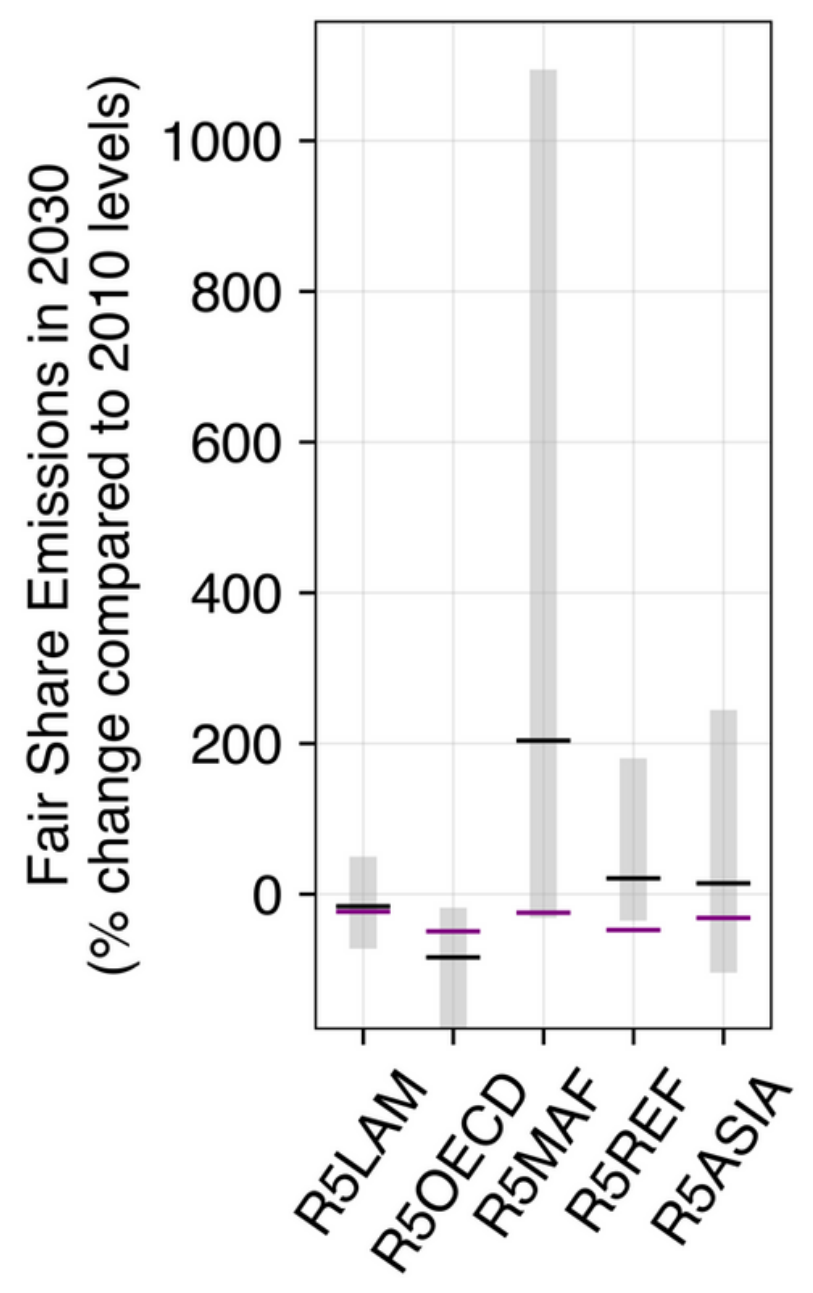

b
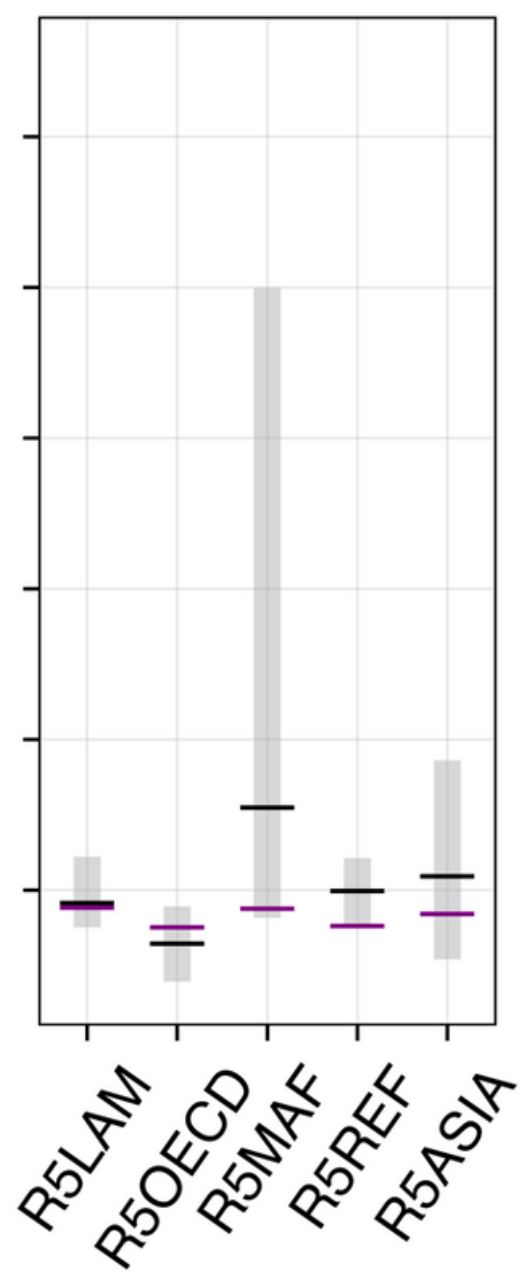

C
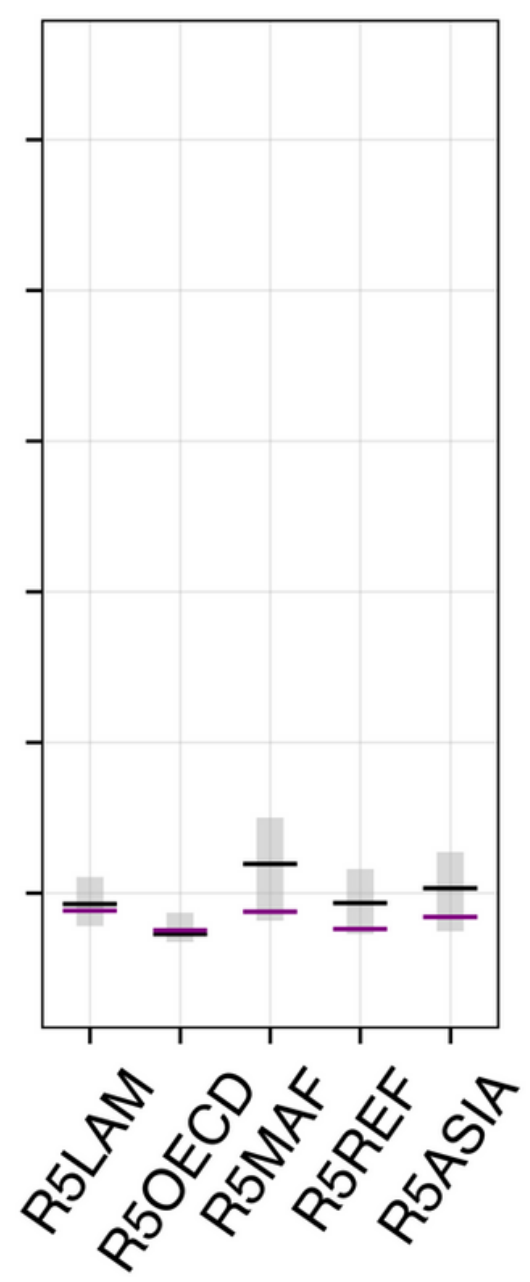

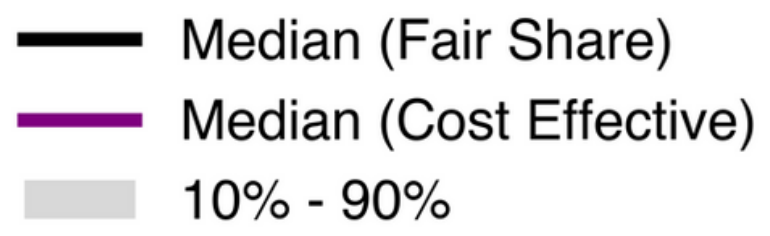

Figure 4

Fair Share Emissions for a $1.5^{\circ} \mathrm{C}$ Low Overshoot Scenario Across the R5 regions for (a) Min/Max (Linear Walk) case, (b) 5th/95th percentile (Linear Walk) case, and (c) Min/Max (Distribution Walk) case. The ranges presented in this figure are for the 10th - 90th percentile of the estimates, where ranges consist of the population of point estimates for all countries comprising a given region. 


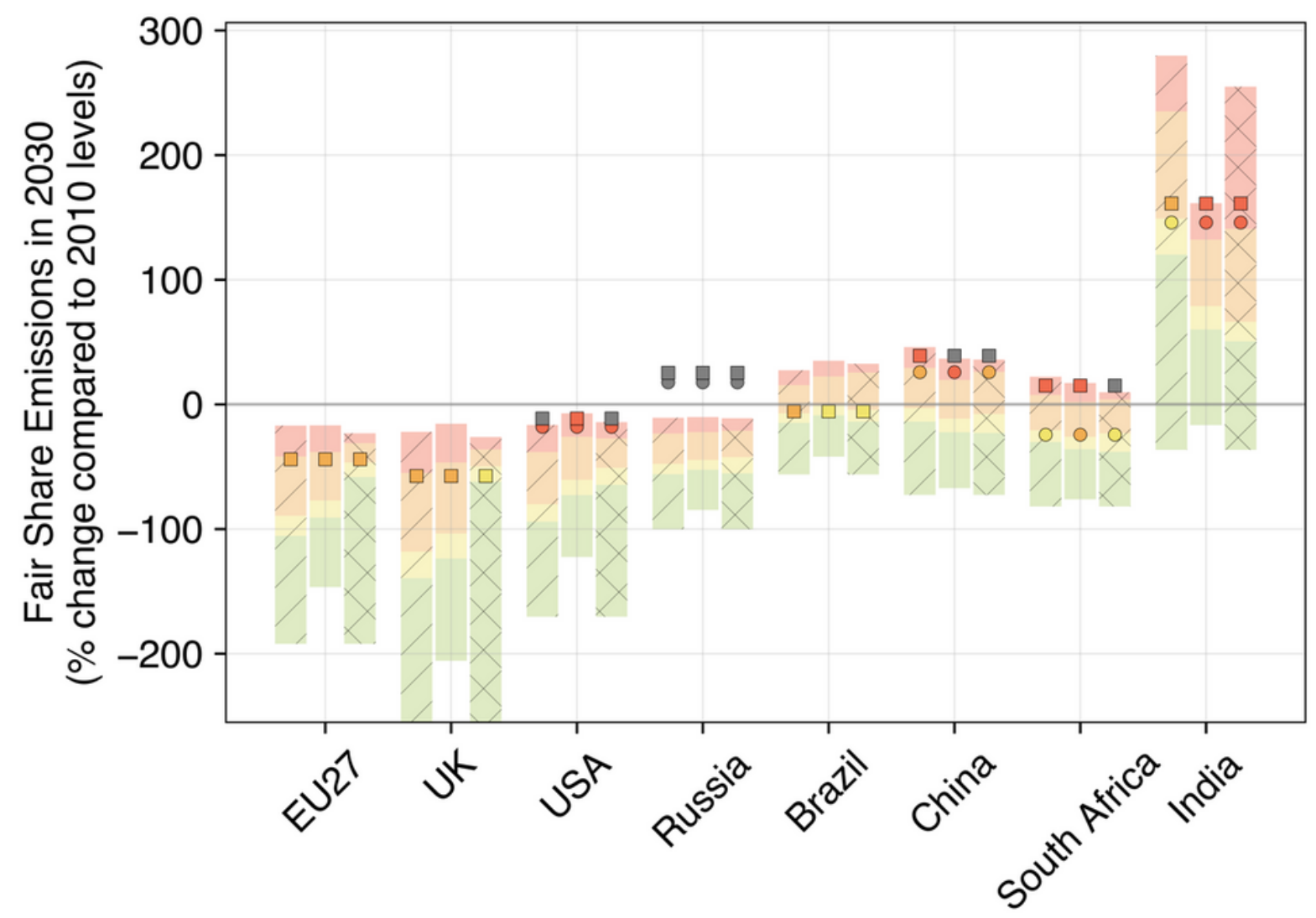

- NDC (high)

- NDC (low)

\section{$1.5^{\circ} \mathrm{C}$ fair share}

$2^{\circ} \mathrm{C}$ fair share $3^{\circ} \mathrm{C}$

$4^{\circ} \mathrm{C}$
Min/Max (Linear Walk) 5th/95th percentile (Linear Walk) Min/Max (Distribution Walk)

Figure 5

Country-level results compared across the three cases. For the USA, we assess a hypothetical NDC that is set at current policy projection levels. NDC estimates are colored based on the temperature category into which they fall for each case.

\section{Supplementary Files}

This is a list of supplementary files associated with this preprint. Click to download.

- supplementfairsharesupload.xlsx

- supplementaryinformation.docx 